\title{
Desafios para a inclusão no mercado de trabalho de pessoas com deficiência intelectual: experiências em construção*
}

\section{Challenges for the inclusion of the labor marked people with intellectual disability: ongoing experiences}

\author{
Rosé Colom Toldrá1, Cecília Berni De Marque², \\ Maria Inês Britto Brunello ${ }^{3}$
}

TOLDRÁ, R. C.; De MARQUE, C. B.; BRUNELLO, M. I. B. Desafios para a inclusão no mercado de trabalho de pessoas com deficiência intelectual: experiências em construção. Rev. Ter. Ocup. Univ. São Paulo, v. 21, n. 2, p. 158-165, maio/ago. 2010.

RESUMO: O estudo buscou refletir sobre as experiências voltadas à preparação e inclusão no mercado de trabalho de pessoas com deficiência intelectual desenvolvidas por instituições especializadas. A pesquisa foi realizada em 2007, por meio de entrevistas aos profissionais das instituições. Evidenciou-se a preocupação das instituições quanto à qualificação e atualização dos projetos e ações para a inclusão de seus usuários no mercado formal ou informal de trabalho. As principais dificuldades para a inclusão no mercado de trabalho são decorrentes da desinformação e desconhecimento da sociedade acerca da deficiência intelectual, promotoras de atitudes preconceituosas, da defasagem entre as exigências das empresas e o nível de formação e escolarização dos indivíduos. As contratações estão, geralmente, atreladas às exigências das legislações e o oferecimento de vagas nem sempre são compatíveis com as possibilidades dos indivíduos. Porém, verificam-se alguns avanços em direção à profissionalização e inclusão das pessoas com deficiência intelectual no mercado de trabalho.

DESCRITORES: Pessoas com deficiência/legislação \& jurisprudência; Capacitação profissional; Instituições. Mercado de trabalho; Legislação; Defesa das pessoas com deficiência/legislação \& jurisprudência; Terapia ocupacional.

\footnotetext{
* Artigo elaborado a partir de pesquisa financiada pela PUC-Campinas.

1. Prof ${ }^{\mathrm{a}}$. Dr ${ }^{\mathrm{a}}$. do Curso de Terapia Ocupacional do Departamento de Fisioterapia, Fonoaudiologia e Terapia Ocupacional da FMUSP.

2. Terapeuta Ocupacional da Associação para Deficientes Visuais - ADEVISA.

3. Prof ${ }^{\mathrm{a}}$. Dr ${ }^{\mathrm{a}}$. do Curso de Terapia Ocupacional do Departamento de Fisioterapia, Fonoaudiologia e Terapia Ocupacional da FMUSP.

Endereço para correspondência: Departamento de Fisioterapia, Fonoaudiologia e Terapia Ocupacional da FMUSP. Rua Cipotânea, ${ }^{\circ}$ 51 Cidade Universitária. São Paulo - SP CEP: 05360-160. E-mail: maribrunello@hotmail.com
} 
TOLDRÁ, R. C. et al. Desafios para a inclusão no mercado. Rev. Ter. Ocup. Univ. São Paulo, v. 21, n. 2, p. 158-165, maio/ago. 2010.

\section{INTRODUÇÃO}

$\mathrm{H}$

istoricamente, os processos de exclusão

das pessoas com deficiência intelectual

impostos pela sociedade, têm dificultado o

acesso desses indivíduos a determinados bens essenciais como saúde, educação e trabalho. Os problemas decorrentes deste fato são a baixa escolaridade, dificuldade de inserção social, pouca circulação e uso dos espaços públicos e comprometimento para desempenhar as atividades profissionais. Como afirmam Ferronatto et al. (2008), a lógica de exclusão social conseqüente da desinformação e preconceito conduz a atitudes e práticas que dificultam ou impossibilitam as oportunidades e o acesso ao mercado de trabalho.

Segundo a International Association for the Scientific of Intellectual Disabilities (AAIDD) de 2002, a deficiência intelectual acomete as pessoas antes dos dezoito anos de idade e caracteriza-se por limitações significativas no funcionamento intelectual e nas habilidades adaptativas. As limitações são compreendidas a partir de uma perspectiva multidimensional, proposta em cinco dimensões: habilidades intelectuais; comportamento adaptativo; participação, interação e papéis sociais; saúde física e mental e contextos relacionados ao ambiente e condições sócio-culturais (CARVALHO; MACIEL, 2003).

Desta forma, a deficiência intelectual deixa de ser identificada como um traço absoluto manifestado pela pessoa e classificada com base em níveis de coeficiente de inteligência (leve, moderado, severo e profundo), passando a ser compreendida como expressão da interação entre o indivíduo e o meio ambiente em que vive e avaliada a partir de níveis de apoio ou suporte necessários ao desempenho e exigências ambientais (CARVALHO; MACIEL, 2003).

O cenário atual indica mudanças significativas na relação da sociedade para com as pessoas com deficiência. De acordo com a proposta elaborada pelas Nações Unidas (NACIONES UNIDAS, 1995) a sociedade inclusiva se baseia no respeito aos direitos humanos, à liberdade, à diversidade, à justiça social de grupos vulneráveis e marginalizados em busca da participação democrática e do exercício dos direitos. Deste modo, torna-se fundamental a promoção de equiparação de oportunidades e a incorporação de medidas que favoreçam a participação das pessoas com deficiência em todas as esferas da vida.

A inclusão de pessoas com deficiência no mercado de trabalho reflete as mudanças sociais ocorridas nas últimas décadas. Transformações, estas, identificadas pela ampliação do debate acerca dos direitos desses indivíduos, a criação de legislações específicas para inclusão social e no mercado de trabalho.

Considerando que o trabalho tem importante repercussão na vida de todos os indivíduos e é apontado como atividade fundamental para a realização pessoal, desenvolvimento da auto-estima, interação social, sentimento de pertinência e capacidade, bem como, construção de identidade e autonomia (SAINT-JEAN, 2003; NETTO, 2003), as políticas públicas têm dado especial atenção às propostas que buscam promover a participação e inclusão dos indivíduos com deficiência no mercado de trabalho.

De acordo com os dados da Relação Anual de Informações Sociais (RAIS) de 2007, do Ministério do Trabalho e do Emprego, referente à inclusão das pessoas com deficiência no mercado de trabalho, constata-se que dos 37,6 milhões de postos de trabalho apenas 348,8 mil (1\%) são ocupados por pessoas com deficiência e destes $2,4 \%$ têm deficiência intelectual (ALMEIDA, 2009). Os números evidenciam, também, que a exclusão de pessoas com deficiência intelectual nas atividades relacionadas ao trabalho é maior do que em outras deficiências.

Nos últimos anos ganharam posição de destaque, no cenário nacional, as medidas que visam à inclusão desses indivíduos no mercado formal e informal, decorrentes da política de cotas pela Lei 8.213/91, a qual surgiu como um facilitador para inserção de pessoas com deficiência no setor privado. Esta lei prevê que as empresas que possuem 100 ou mais empregados são obrigadas a preencher de $2 \%$ a $5 \%$ dos seus cargos com beneficiários reabilitados ou com pessoas com deficiência (BRASIL, 2007).

Segundo Mendonça (2007), a legislação brasileira é considerada uma das mais avançadas no que diz respeito à inclusão das pessoas com deficiência no mercado de trabalho e possui uma base constitucional e um conjunto de princípios legais que asseguram uma vida digna a essas pessoas. Porém, na prática ainda se encontra muito frágil, indicando ser imprescindível a manutenção das leis bem como a qualificação das ações referentes à profissionalização da população com deficiência para o mercado de trabalho, visando promover e garantir a sua participação (TOLDRÁ; SÁ, 2008).

As oportunidades de acesso ao trabalho das pessoas com deficiência ocorrem de forma lenta e começam a ser incentivadas por meio de fiscalização mais efetiva do Ministério Público do Trabalho (Decreto no 3299/99), mediante punições às empresas que não vêm cumprindo com a lei (FERRONATTO et al., 2008). A fiscalização tornou o tema mais público e possibilitou maior conscientização da população quanto à necessidade de promoção da qualificação destas pessoas (MENDONÇA, 2007). O 
TOLDRÁ, R. C. et al. Desafios para a inclusão no mercado. Rev. Ter. Ocup. Univ. São Paulo, v. 21, n. 2, p. 158-165, maio/ago. 2010.

reconhecimento da necessidade de conscientização das empresas fez com que algumas Sub Regionais de Trabalho e Emprego só adotassem as medidas punitivas após ações educativas de sensibilização e informação às empresas.

Assim, o presente estudo teve como finalidade conhecer os programas realizados por instituições especializadas no atendimento a pessoas com deficiência intelectual, referentes à preparação e inclusão de seus usuários no mercado de trabalho, bem como identificar e compreender as dificuldades e desafios encontrados para sua efetivação.

\section{PERCURSO METODOLÓGICO}

A pesquisa ocorreu em 2007 no Município de Campinas. Constou, primeiramente, de um levantamento e identificação de instituições especializadas no atendimento de pessoas com deficiência intelectual, por meio de consultas em redes de informações eletrônicas e lista telefônica. A partir destes dados foi realizado contato telefônico para confirmação das atividades relacionadas à preparação e inclusão no mercado de trabalho de pessoas com deficiência intelectual. Do total de dez instituições da região que atendiam essa população, três responderam que não desenvolviam programas nesta área, três instituições não foram encontradas via contato telefônico e quatro confirmaram as atividades e concordaram em participar do estudo.

A pesquisa se situa no campo da investigação qualitativa do tipo exploratória (GIL, 2006; MINAYO, 2007). O estudo envolveu entrevistas com um representante de cada instituição (determinados por estas): dois terapeutas ocupacionais e um psicólogo, responsáveis pelos programas voltadas à preparação e inclusão no mercado de trabalho, e um coordenador da instituição, assistente social, que possuía as informações gerais relativas a estas atividades. A técnica adotada para a coleta de dados foi a entrevista, baseada em roteiro de perguntas semi-estruturadas, em que se combinaram questões fechadas e abertas, sendo que estas últimas possibilitaram ao informante discorrer de forma mais livre sobre o tema da pesquisa (MINAYO, 2007). As questões abrangeram: caracterização dos serviços (tempo de funcionamento, abrangência e capacidade de atendimento), dos usuários (faixa etária, gênero, escolaridade e tipos de deficiência) e das ações e programas realizados voltados à preparação para o trabalho e inclusão no mercado de trabalho. As entrevistas foram realizadas no próprio local, o que permitiu visitar o espaço físico e algumas atividades em andamento.

Os dados foram analisados conforme o objetivo geral que buscou conhecer os programas institucionais relacionados à preparação e inclusão de pessoas com deficiência intelectual no mercado de trabalho bem como identificar os desafios encontrados e refletir sobre essas ações.

Para o estudo dos dados adotou-se a análise temática do conteúdo registrado, organizados segundo as etapas descritas por Minayo (2007): pré-análise, exploração do material e retomada dos objetivos para o desenvolvimento de categorias e a análise propriamente dita.

As entrevistas foram realizadas após aprovação da pesquisa pelo Comitê de Ética em Pesquisa da PUCCampinas (protocolo 098/07) e o preenchimento do Termo de Consentimento Livre e Esclarecido pelos participantes.

\section{RESULTADOS E DISCUSSÃO}

As instituições estudadas são referências para o município e regiões próximas de Campinas e se caracterizam por serem Associações ou Organizações não Governamentais (ONG). Possuem longo tempo de funcionamento variando de 20 a 46 anos e com abrangência de atendimento de grande parte da região de Campinas. A população atendida por esses locais era constituída por pessoas com deficiência intelectual (prioritariamente com Síndrome de Down) e, em menor proporção, por pessoas com outras deficiências tais como paralisia cerebral e deficiências múltiplas. A faixa etária das pessoas variou de 16 a 52 anos e, quanto ao gênero, a pesquisa não demonstrou uma significativa diferenciação entre os locais. A escolaridade dos usuários era composta, principalmente, de pessoas não alfabetizadas ou com ensino fundamental incompleto.

Em todas as entrevistas foi mencionado que as instituições tinham como objetivo central realizar ações que contribuam com a inclusão social das pessoas com deficiência intelectual e com a melhora da qualidade de vida e de seus familiares, apesar de apresentarem especificidades em suas propostas. Na maioria dos relatos evidencia-se que para se atingir estas metas é fundamental acompanhar as mudanças sociais atuais, romper com antigas concepções sobre a deficiência intelectual e aprofundar as reflexões sobre as práticas realizadas por elas. Tarefas, consideradas por todas as instituições, bastante complexas para serem atingidas.

Observou-se, de acordo com a Tabela 1, uma diversidade de programas e atividades oferecidos pelas instituições relacionados à preparação para o trabalho, orientação vocacional e inclusão no mercado, tais como: oficinas e cursos, estágios profissionalizantes, assessoria às empresas, trabalho apoiado, grupos de geração de 
TOLDRÁ, R. C. et al. Desafios para a inclusão no mercado. Rev. Ter. Ocup. Univ. São Paulo, v. 21, n. 2, p. 158-165, maio/ago. 2010.

renda e cooperativas. Estas variavam de acordo com a trajetória e experiências de cada local, com a capacidade de atendimento, instalações do serviço, propostas da coordenação e vinculação com outras instituições.

Tabela 1 - Número de participantes, profissionais entrevistado, programas e atividades desenvolvidas pelas instituições

\begin{tabular}{|c|c|c|c|c|c|c|}
\hline Inst. & $\begin{array}{l}\text { Profissional entre- } \\
\text { vistado }\end{array}$ & $\begin{array}{l}N^{\circ}{ }^{\circ} \\
\text { Part }\end{array}$ & Tipo de Deficiência & $\begin{array}{l}\text { Programas voltadas ao } \\
\text { trabalho }\end{array}$ & $\begin{array}{l}\text { Atividades em convênio/ } \\
\text { parceria }\end{array}$ & $\begin{array}{l}\text { Atividades complemen- } \\
\text { tares }\end{array}$ \\
\hline A & $\begin{array}{l}\text { Terapeuta Ocupa- } \\
\text { cional }\end{array}$ & 168 & $\begin{array}{l}\text { Maioria deficiência } \\
\text { intelectual e alguns ca- } \\
\text { sos associados a outras } \\
\text { deficiências }\end{array}$ & $\begin{array}{l}\text { *Programa educação pro- } \\
\text { fissional: } \\
\text { - iniciação profissional } \\
\text { - cursos de qualificação: em- } \\
\text { pacotador, repositor, práticas } \\
\text { de escritório, jardinagem } \\
\text { e iniciação ao paisagismo, } \\
\text { preparação de alimentos, } \\
\text { horticultura, artesanato, } \\
\text { confeitaria } \\
\text { - cursos básicos artesanais } \\
\text { *Grupo de geração de renda }\end{array}$ & $\begin{array}{l}\text { *Formação profissional } \\
\text { SENAI } \\
\text { *Estágio e colocação } \\
\text { profissional } \\
\text { *Assessoria às empresas } \\
\text { *Cooperativa de trabalho }\end{array}$ & $\begin{array}{l}\text { *Atendimentos especializa- } \\
\text { dos (fo-noaudiologia, terapia } \\
\text { ocupacional, } \\
\text { fisioterapia, psicologia) } \\
\text { *Grupos de acompanha- } \\
\text { mento } \\
\text { *Lazer e convivência na } \\
\text { instituição }\end{array}$ \\
\hline B & Psicólogo & 23 & Deficiência Intelectual & $\begin{array}{l}\text { *Formação para o trabalho: } \\
\text { - grupo para autonomia } \\
\text { - iniciação para o trabalho } \\
\text { *Oficina de marcenaria }\end{array}$ & $\begin{array}{l}\text { *Estágios de formação } \\
\text { nas empresas } \\
\text { *Assessoria às empresas }\end{array}$ & $\begin{array}{l}\text { *Acompanhamento profis- } \\
\text { sional } \\
\text { na instituição fase de } \\
\text { estágio }\end{array}$ \\
\hline $\mathrm{C}$ & Coordenador & 25 & Deficiência intelectual & $\begin{array}{l}\text { *Preparação para o trabalho } \\
\text { - descobrindo o trabalho } \\
\text { - oficina sócio educativa de } \\
\text { marcenaria }\end{array}$ & $\begin{array}{l}\text { *Estágios de formação na } \\
\text { prefeitura } \\
\text { *Cursos pela CEPRO- } \\
\text { CAMP e outros }\end{array}$ & $\begin{array}{l}\text { * Grupo de dança, música } \\
\text { e teatro } \\
\text { *Após estágio retorno as } \\
\text { atividades da instituição }\end{array}$ \\
\hline $\mathrm{D}$ & $\begin{array}{l}\text { Terapeuta Ocupa- } \\
\text { cional }\end{array}$ & 20 & $\begin{array}{l}\text { Maioria deficiência } \\
\text { Intelectual e alguns ca- } \\
\text { sos associados a outras } \\
\text { deficiências }\end{array}$ & $\begin{array}{l}\text { *Programa de preparação } \\
\text { para o trabalho } \\
\text { - introdução ao trabalho } \\
\text { - oficina de jardinagem, de } \\
\text { artesanato e bazar. }\end{array}$ & $\begin{array}{l}\text { *Aprendizagem profissio- } \\
\text { nal nas empresas } \\
\text { *Assessoria às empresas } \\
\text { *Cursos pela SORRI }\end{array}$ & $\begin{array}{l}\text { *Acompanhamento profis- } \\
\text { sional } \\
\text { *Projeto de educação física, } \\
\text { dança e informática }\end{array}$ \\
\hline
\end{tabular}

Os profissionais entrevistados relataram que ofereciam, também, aos seus usuários palestras, aulas e outras estratégias, nos quais abordavam temas relacionados ao ambiente de trabalho como: relações pessoais e organograma; responsabilidade, assiduidade e pontualidade; regras e normas institucionais (uso de uniforme e equipamentos de proteção); auto-cuidado e aparência pessoal; e atividades instrumentais para a vida diária (utilização de dinheiro, transporte público, preparação para realização de entrevistas e preparação de currículo).

Conforme assinalado pelos profissionais, grande parte das inclusões no mercado de trabalho se deu a partir da procura das empresas pelas instituições. As empresas estabeleciam um determinado perfil de trabalhadores e cabia à instituição o levantamento e encaminhamento de pessoas que correspondiam àquelas demandas. Fica claro o papel das instituições especializadas de intermediadora entre sujeito a ser contratado e a empresa, facilitando o processo de inclusão, preparação profissional e aquisição de habilidades para maior independência e autonomia.
As contratações ocorriam, muitas vezes, pela obrigatoriedade em responder à legislação de política de cotas e em menor número por acreditarem nas capacidades profissionais do empregado. Alguns relatos identificavam que os casos de inclusão não bem sucedidos ocorriam não pela condição da deficiência intelectual, mas devido às exigências do próprio trabalho, o que provavelmente comprometeria o desempenho de qualquer pessoa.

Um dado importante comentado pelos entrevistados foi que na prática as legislações nacionais que asseguram o direito ao trabalho das pessoas com deficiência, ainda, são insuficientes para uma mudança de olhar e aceitação do convívio com a diversidade, tendo em vista que, muitas vezes, as contratações ocorrem pela obrigatoriedade de cumprimento das leis vigentes e não pelo reconhecimento das capacidades profissionais e pessoais desses indivíduos.

Foi possível destacar, da análise das entrevistas, cinco unidades temáticas mais relevantes, conforme descritas a seguir: 
- Importância de parcerias com outros equipamentos de formação profissional e empresas.

A ampliação de vínculos com outros equipamentos de formação e com as empresas foi considerada, de acordo com os entrevistados, uma estratégia para melhorar a qualificação para o mercado de trabalho e ampliar as oportunidades de inclusão da pessoa com deficiência intelectual.

Segundo os profissionais, convênios com instituições profissionalizantes como: Serviço Nacional de Aprendizagem Industrial (SENAI), Centro de Educação Profissional Prefeito Antonio da Costa Santos (CEPROCAMP) e SORRI-Campinas possibilitaram ampliação da inclusão dos usuários no trabalho, adequação e certificação dos cursos oferecidos, além da criação de parcerias de estágios nas empresas visando à formação e posterior contratação no mercado de trabalho.

Porém, em uma das entrevistas foi relatado que os estágios nestes locais não garantiam, necessariamente, a contratação de seus aprendizes, uma vez que eles se deparavam com um mercado de trabalho extremamente competitivo e com exigências, impostas pelas empresas, acima de suas habilidades e conhecimentos. Esta situação era reforçada por parte de muitas famílias que apoiavam que a manutenção dos filhos na condição de estagiários, mesmo que periódicos, ao invés da real inclusão no mercado de trabalho. Os familiares consideravam mais seguro esta forma de vinculação institucional, que favorecia a manutenção do benefício recebido pela previdência, o qual poderia ser perdido com o ingresso no mercado formal e, ainda, poderia correr o risco de demissão.

\section{- Desinformação como geradora de barreiras para a contratação.}

As principais dificuldades mencionadas pelos profissionais para a colocação de seus usuários no mercado de trabalho referiram-se ao estigma em relação às pessoas com deficiência, que ficava mais evidente no caso da deficiência intelectual.

Além disso, o pouco esclarecimento das empresas sobre as legislações relativas à inclusão das pessoas com deficiência no trabalho formal e informal, bem como a desinformação sobre as potencialidades e capacidades desta população, contribuíam para a manutenção de sua imagem como indivíduos incapazes, dependentes e, conseqüentemente, impossibilitados para aprenderem e assumirem atividades de trabalho.
Esta situação exigiu das instituições especializadas o desenvolvimento de estratégias que viabilizassem gerar programas adequados para a inclusão destas pessoas através de trocas de informações entre empresa e instituição, esclarecimentos e palestras temáticas e do acompanhamento das atividades no próprio ambiente de trabalho.

- Necessidade de adequação das propostas das instituições especializadas às exigências do mercado de trabalho e realidade social.

Constatou-se que uma das instituições possuía maior diversidade de programas voltados à qualificação profissional e atividades de apoio à inclusão no trabalho. Oferecia cursos básicos artesanais (não mais oficinas ocupacionais) para os usuários que não eram absorvidos pelo mercado competitivo. Estes cursos visavam à inclusão na forma de trabalho autônomo, por meio de cooperativas sociais e grupos de geração de renda com vistas à desinstitucionalização de seus usuários. Apresentava uma visão mais crítica em relação às oficinas ocupacionais, em decorrência das novas concepções de deficiência e das atuais exigências do mundo do trabalho.

Três das quatro instituições pesquisadas desenvolviam propostas que mesclavam atividades de aprendizagem de habilidades e vivências de preparação para o trabalho, com intervenção da equipe de profissionais junto aos usuários, apoiando-se nas idéias das oficinas terapêuticas. Um dos entrevistados referiu-se à necessidade de se rever os próprios programas oferecidos para as pessoas com deficiência intelectual, que fossem na contramão da desinstitucionalização, e defendia que o aprendizado ocorresse na própria empresa contratante, visando uma aproximação com a realidade das organizações e do perfil profissional esperado.

Verificou-se, como afirmam Ferronatto et al. (2008), a importância de uma melhor preparação e qualificação profissional das pessoas com deficiência, da inserção escolar desde a infância, e do oferecimento de atividades que contribuíssem para o desempenho de diferentes papéis sociais. Isto requer, conforme assinala um dos entrevistados, uma mudança de atitude tanto das empresas como das instituições especializadas no sentido de valorizar as potencialidades dos usuários garantindo a real inclusão social.

A fim de aprimorar e melhor acompanhar o processo de colocação profissional, uma das instituições destacou a necessidade de realizar periódicas avaliações junto aos usuários quanto à satisfação da própria pessoa no local de trabalho. 
TOLDRÁ, R. C. et al. Desafios para a inclusão no mercado. Rev. Ter. Ocup. Univ. São Paulo, v. 21, n. 2, p. 158-165, maio/ago. 2010.

- Acompanhamento e suporte contribuem para a contratação e permanência da pessoa com deficiência intelectual no mercado de trabalho.

Três profissionais entrevistados relataram diversas intervenções que contribuíam para viabilizar os estágios nas empresas ou mesmo a contratação e a permanência no trabalho. Assim, eram oferecidas às empresas assessoria para a análise da função e adequação do posto de trabalho; esclarecimentos e orientações aos profissionais das empresas sobre a deficiência intelectual, bem como acompanhamento durante a colocação profissional. Duas instituições disponibilizavam, aos usuários, a continuidade dos atendimentos especializados ou a participação em alguma atividade projeto na própria instituição durante a fase de estágio/aprendizagem, ou mesmo após a inserção no mercado de trabalho.

Conforme aponta Carvalho e Maciel (2003), os diversos tipos de suporte que podem ser oferecidos às pessoas com deficiência intelectual pelas instituições e empresas são fundamentais para propiciar o aprendizado das habilidades nos locais de trabalho, a credibilidade nas competências destas pessoas e o processo de inclusão no mercado. Segundo os entrevistados, o desenvolvimento de habilidades para o trabalho requer cooperação entre instituição que atende essa população e a empresa contratante como também o acompanhamento do processo de inserção no trabalho. Deste modo é fundamental que as empresas encarem a inclusão de pessoas com deficiência no contexto do trabalho como uma base para mudanças de atitudes, considerando as diferenças e as singularidades dos indivíduos (ROSS, 2006; TOLDRÁ, 2009).

Em uma das instituições, o acompanhamento era realizado no próprio local e o profissional especializado procurava manter-se o menor tempo possível na empresa para que sua intervenção não se caracterizasse como uma ação terapêutica ou de ensino. Por este motivo a assessoria à empresa era realizada no horário em que a pessoa não se encontrava no espaço de trabalho.

Outras iniciativas eram incentivadas, como a disponibilidade da estrutura física da instituição, aos finais de semana, às pessoas com deficiência, familiares e comunidade para o desenvolvimento de atividades esportivas e de lazer visando à ampliação de espaços de convivência e a promoção de bem estar. Segundo Almeida (2007), é esperado que a pessoa com deficiência, como qualquer outro indivíduo, realize, concomitantemente à sua formação profissional, outras atividades que enriqueçam sua vida. Assim, para o autor o horário e o tipo de emprego precisam ser compatíveis e flexíveis para a realização destas outras atividades.

- Escolarização da pessoa com deficiência intelectual e as exigências do mercado de trabalho.

A exigência de escolaridade manifestada pelas empresas para a colocação profissional (em geral do primeiro grau) foi apontada nas entrevistas como questão relevante, uma vez que, a maior parte dos indivíduos com deficiência intelectual tinha um histórico de abandono e de fracasso escolar.

Esta exigência tem demandado, segundo os profissionais, a ampliação e valorização das atividades pedagógicas realizadas pelas instituições e apoio ao retorno escolar dos usuários, em locais de ensino como a Fundação Municipal para Educação Comunitária (FUMEC) e Ensino de Jovens e Adultos (EJA). Conforme relatado a convivência com o ambiente escolar tem favorecido a aprendizagem, o desenvolvimento de habilidades e a ampliação de oportunidades de formação, trabalho e estilos de vida mais inclusivos para as pessoas com deficiência intelectual e suas famílias.

Todos os profissionais entrevistados criticaram a imposição do ensino fundamental para o ingresso no mercado de trabalho e apontaram, conforme os autores De Marque e Toldrá (2008), a necessidade de maior flexibilidade das empresas quanto às exigências do ensino formal, para a adaptação à realidade destas pessoas. Estes indicaram, ainda, a necessidade de valorização de outros atributos para o trabalho e, não somente, o aprendizado de habilidades relacionadas à escrita e leitura, já que este era considerado como um dos maiores entraves vivenciado pelas pessoas com deficiência intelectual para o ingresso no mercado de trabalho. Pesquisas apontam como forma de superação, maior conscientização dos empresários a respeito das potencialidades e possibilidades dos indivíduos com deficiência (TOLDRÁ; SÁ, 2008; SHIMONO, 2009).

Segundo os profissionais entrevistados, grande parte das famílias demonstrava pouco conhecimento sobre os direitos de inclusão escolar das pessoas com deficiência bem como sobre as diversas possibilidades de inserção no mercado de trabalho formal e informal. Esta realidade tem demandado das instituições a criação de projetos no sentido de sensibilizar e informar as famílias, a fim de gerar práticas mais integradas e possibilitar um acompanhamento mais próximo junto a seus filhos. Destacando-se o papel que desempenham as instituições no tecido social na medida em que contribuem com as mudanças do contexto (ARAÚJO et al., 2006; GUGEL, 2007).

O estudo assinala, conforme mostra a literatura (DE 
TOLDRÁ, R. C. et al. Desafios para a inclusão no mercado. Rev. Ter. Ocup. Univ. São Paulo, v. 21, n. 2, p. 158-165, maio/ago. 2010.

MARQUE; TOLDRÁ, 2008; SHIMONO, 2009), para a necessidade de mudanças e aprimoramento relacionados à qualificação profissional e ampliação das oportunidades de trabalho, através de uma postura de valorização das potencialidades das pessoas com deficiência intelectual e maior articulação da formação profissional com a educação básica e/ou educação de jovens e adultos.

\section{CONSIDERAÇÕES FINAIS}

Com o estudo verificou-se que as instituições têm buscado reelaborar e construir novas práticas que qualifiquem e atualizem os programas voltados à preparação e inclusão no mercado de trabalho de pessoas com deficiência intelectual. Isto tem demandado repensar as relações e as práticas protecionistas e adotar iniciativas que fomentem a inclusão social, equiparação de oportunidades e defesa dos direitos, em conjunto com as famílias e a sociedade.

As contribuições das instituições especializadas ficam presentes na intermediação das diferentes situações, tanto no que se refere à aquisição de habilidades, preparação para o trabalho e na facilitação do processo de inclusão no mercado. Para tanto, é necessário superar o viés assistencialista e filantrópico que permeiam as práticas institucionais voltadas a essa população para que possibilitem a efetiva inclusão.

Evidencia-se no estudo a importância de se atualizar e reavaliar as referências e concepções que fundamentam os conceitos acerca das pessoas com deficiência intelectual, bem como ampliar as informações no sentido de modificar as atitudes geradoras de situações de exclusão vividas pelas mesmas. $\mathrm{O}$ desconhecimento e a desinformação geram preconceitos e dificultam as oportunidades de inclusão social, e ao contrário, o acesso a informação adequada é considerado um poderoso instrumento de sensibilização para o desenvolvimento social e respeito à diversidade no trabalho.

Cabe as empresas disseminarem o reconhecimento pela igualdade de oportunidades a partir de um fazer compartilhado, cooperativo com as instituições e a sociedade, pautado na ética das relações humanas e valorização da diversidade, objetivando-se a construção de uma sociedade mais justa e igualitária, por meio da inclusão das pessoas com deficiência intelectual no mercado de trabalho.

TOLDRÁ, R. C.; De MARQUE, C. B.; BRUNELLO, M. I. B. Challenges for the inclusion of the labor marked people with intellectual disability: ongoing experiences. Rev. Ter. Ocup. Univ. São Paulo, v. 21, n. 2, p. 158-165, maio/ago. 2010.

\begin{abstract}
S: The study tries to understand the experiences about the preparation and labor inclusion of people with intellectual disability developed by specialized institutions. The study was made in 2007 by means of interviews with representatives of the institutions. It brought to light the preoccupation of the institutions regarding the quality and implementation of projects directed towards the inclusion of their actions in the formal and informal job market. The difficulties of inclusion come from the lack of knowledge and disinformation about intellectual disability, which creates prejudiced attitudes, and the demands of enterprises concerning the level of schooling required for work. Moreover, the majority of enterprises consider the demands of legislation and jobs are not always compatible with this population. However, some advances were observed in respect to professionalism and labor inclusion of people with intellectual disability.
\end{abstract}

KEY WORDS: Disability persons/legislation \& jurisprudence; Professional training; Institutions; Job market; Legislation; Handicapped advocacy/legislation \& jurisprudence; Occupational therapy.

\title{
REFERÊNCIAS
}

ALMEIDA, M. S. R. Empregabilidade da pessoa com síndrome de Down. Intituto Inclusão Brasil, 2007. Disponível em: http:// saci.org.br/index.php?modulo=akemi\&parametro=20054 . Acesso em: 14 maio 2009.

ARAÚJO, E. A. C. et al. Planejamento e organização de serviços. In: GOYOS, C.; ARAÚJO, E. (Org). Inclusão social: formação do deficiente mental para o trabalho. São Carlos: RiMa, 2006.

BRASIL. Ministério do Trabalho e Emprego. A inclusão das pessoas com deficiência no mercado de trabalho. Brasília: MTE, SIT, DEFIT, 2007.

CARVALHO, E. N. S.; MACIEL, D. M. M. A. Nova concepção 
TOLDRÁ, R. C. et al. Desafios para a inclusão no mercado. Rev. Ter. Ocup. Univ. São Paulo, v. 21, n. 2, p. 158-165, maio/ago. 2010.

de deficiência mental segundo a American Association on Mental Retardation - AAMR: sistema 2002. Temas Psicol. SBP, v. 11, n. 2, p. 147-156, 2003.

DE MARQUE, C. B. TOLDRÁ, R. C. Profissionalização de pessoas com deficiência mental no Município de Campinas: estudo de programas e projetos. In: XII Encontro de Iniciação Científica da PUC-Campinas, 2008, Campinas. Anais. Campinas, 2008.

FERRONATTO et al. Inclusão laboral da pessoa portadora de deficiência. Rev. Digital (Buenos Aires). v. 12, n. 117. Disponível em: http://www.efdeportes.com. Acesso em: 12 fev. 2008.

GIL, A. C. Métodos e técnicas de pesquisa social. São Paulo: Atlas, 2006.

GUGEL, M. A. Pessoas com deficiência e o direito ao trabalho. Florianópolis: Obra Jurídica, 2007.

MENDONÇA, R. C. T. Breves comentários sobre os dispositivos legais que subsidiam a política de inclusão das pessoas com deficiência no mercado de trabalho. 2007. Disponível em: htp//:saci.org.br/index.php?modulo=akemi\&parametro=19683. Acesso em: 22 jun 2009.

MINAYO, M. C. S. O desafio do conhecimento: pesquisa qualitativa em saúde. São Paulo: Hucitec, 2007.
NACIONES UNIDAS. Propuestas de acción para las personas con discapacidad. Buenos Aires: Lúmen, 1995.

NETTO, J. M. F. Sexualidade e trabalho. In: OLIVEIRA, M. H. A. (Org.). Trabalho e deficiência mental: perspectivas atuais. Brasília, D.F.: Dupligráfica Ed., 2003. p. 93-110.

ROSS, P. R. Trabalho das pessoas com deficiência: transformando barreiras em oportunidades. In: MANZIN, E. J. (Org.). Inclusão e acessibilidade. Marília: ABPEE, 2006.

SAINT-JEAN, M. Organização do trabalho e saúde mental. Rev. Ter. Ocup. Univ. São Paulo, v. 14, n. 3, p. 48-51, 2003.

SHIMONO, S. O. Educação e trabalho: caminhos da inclusão na perspectiva da pessoa com deficiência. 2009. Dissertação (Mestrado), Universidade de São Paulo, São Paulo, 2009.

TOLDRÁ, R. C.; SÁ, M. J. C. N. A profissionalização de pessoas com deficiência em Campinas: fragilidades e perspectivas. Rev. Ter. Ocup. Univ. São Paulo, v. 19, n. 1, p. 48-55, 2008.

TOLDRÁ, R. C. Políticas afirmativas: opinião das pessoas com deficiência acerca da legislação de reserva de vagas no mercado trabalho. Rev. Ter. Ocup. Univ. São Paulo, v. 20, n. 2, p. 110$117,2009$. 